\title{
The Silkworm, Bombyx mori: A Promising Model Organism to Study the Longevity - A Review
}

\author{
M.N. Ramya ${ }^{1}$, Shivkumar ${ }^{2}$ and T.S. Jagadeesh Kumar $^{1}$ \\ ${ }^{1}$ Silkworm Physiology and Biochemistry Laboratory, Department of Studies in Sericulture \\ Science, Manasagangothri, University of Mysore, Mysore-570006, Karnataka, India \\ ${ }^{2}$ Central Sericultural Research and Training Institute, Central Silk Board, Pampore, Jammu \\ and Kashmir-192121, India \\ *Corresponding author
}

\section{Keywords}

Bombyx mori, Longevity (aging), Intrinsic and extrinsic factors.

Article Info

Accepted: 04 October 2018 Available Online: 10 November 2018

\section{A B S T R A C T}

The silkworm Bombyx mori being a typical representative of lepidopteron insects is of great economic importance in terms of longevity having short generation time, wherein physiological, genetical, molecular and biological aspects are playing an important role. But, the mechanism of longevity has been gradually unraveled due to not realizing indepth in basic theoretical and practical fundamentals for the several above said aspects of insects in particularly silkworm Bombyx mori. In spite of the fact, application of several biotechnological methods have been implementing in the era of advanced biology. Silkworm has to be a model organism to study the longevity, because it is an economically important insect for the silk production, wherein longevity play an important role in metabolic activities during its life cycle and understanding of its durability to reduce still shorter is the need of hour for the benefit of rearer, breeders, physiologist, biochemist, geneticist, farmers, etc in economic \& scientific point of view. Regretfully, the application of theoretical and practical based theories are not possible until unless the efforts of converting into the action through proper research investigations and during various movements/programmes to reach the knowledge of longevity in a systematic way for the users. In the light of the above concept, herein this review, summarized the several important aspects are directly or indirectly influencing/effecting on longevity with providing authentically supporting evidences to understand the impact of age-related disorders for the standardization of life span in the insects with special reference to the Bombyx mori. The information gathered and discussed herein is a first ever effort as a review and greatly be helps to further research investigations in the field of gerontology with reference to silkworm Bombyx mori.

\section{Introduction}

The word insect originated from Latin, it means "cut into sections" and insects are belong class invertebrates within the arthropod phylum, those all are having chitinous exoskeleton, dividing its body into three parts namely, head, thorax and abdomen. However, insects are most different classes among the animals on the earth and which have been 
identified as more than one million species and representing greater than half of all known living organisms (Chapman, 2006 and Wilson, 2009). It is estimated fact that, potentially greater than $90 \%$ of the differing animals living forms on earth (Erwin and Terry, 1982), except few numbers of species reside in ocean but remaining all species found in nearby all environments. Further, life cycles of the insects vary depending upon the species but most of the insects' hatches from eggs and undergo series of moulting, pupal, adult, metamorphosis stages, etc., (Chapman, 2006).

However, the insect silkworm Bombyx mori have being a representative group of Lepidoptera insects is of great economic importance in the silkworm industry. Silkworm is a model insect in lepidopteran group for its clear genetic background and having short generation time and it has highly beneficial organism in the life science (Meng et $a l ., 2017)$. The life cycle of the silkworms depending upon the voltinism (Uni-BiMultivoltine races) and it also undergo four moults and five instars. Generally, Culturing of silkworm itself is known as "silk culture or sericulture" which has been practicing since around 5000 years in china (Goldsmith et al., 2004). It is believed fact that, the silk culturing or producing of silk kept many year secret in china for several years. But even though presently china $(146,000 \mathrm{MT})$, India $(28,708$ MT) and Uzbekistan (1,100 MT) are the three countries have occupied first, second and third positions respectively in the raw silk production and $60 \%$ of world silk producing by two countries alone (China \& India).

Life is a journey in the journey could not realize the durability in sometimes and other word can be says "longevity of life". It can be defined as some times meant to refer only to especially long live members of a population and also used this term as an aging or "life expectancy" in demography. Aging is a complex process that involves the number of deleterious changes resulting in overall decline in several important physiological functions e.g. Energy imbalance, consumption of high caloric food, causing of several diseases, unbalancing genetic molecular mechanisms and their associated metabolic disorders in totally overall leads to lower physiological activities of the particular organism and eventually causing several diseases and leading to death at ultimate due to misbalancing immune system, which is said to be most important host-defence mechanism in human and also highly conserved in insects particularly in silkworm Bombyx mori. Hence, keeping above concept in the mind, a review survey has made to understand the importance of aging mechanism factors for causing longevity, intrinsic, extrinsic and some biochemical factors influences aging in insects and particularly in silkworm Bombyx mori.

\section{Origin of ageing and background aspects}

Prior to the several decades ago, many groups of insects have evolved with different percentage-wise including lepidopteron silkworm group (Figure 1) and numerous gerontologists have researched on the aging phenomenon in insects too. During $20^{\text {th }}$ century "proximate" (mechanistic) and "ultimate" (evolutionary) are the two theories of aging, which have positively linked among each other, because to understand their interaction and shared questions, which generated the better information comprehension of aging and evolution of life spans in multicellular organisms (Cohn et al., 2010 and McGraw et al., 2010).

But, generally, the definition of aging so far yet to be have solid authentication and does not exist universally in the world. However, an American gerontologist has given basic characteristic phenomenon by means of postulating four associated phenomenon (Fig. 2). Further, Jose Vana et al. (2007) have 
clearly revealed through presenting different consequences influencing on aging (Fig. 3) and there are more than 300 theories, which are associated with aging and still number is increasing (Mevdevev, 1990). But, Hamilton, (1966) and Charles worth, (1980) have reported that, aging is a biological phenomenon and based on which mainly three important theoretic theories gives in exactly what and how theories of aging originated. These theoretic theories are based on fact of extrinsic mortality which leads to decrease of natural selection with aging.

\section{Mutation accumulation theory}

This is the theory which gives some biological clues to think over aging phenomenon in insects. The scientist Medawar, (1952) who has predicted through observing slight effect in genome of an organism, which leads to change in physiological organs associated with the aging.

\section{Antagonistic pleiotropy theory}

Several years later, the second theory further associated with first theory, through with slight information on aging, which has investigated by Williams, (1957) who suggested that, it is an active mechanism takes place in insects where how mutation causes aging and introduces a theory called antagonistic pleiotropy theory.

\section{Disposable some theory of aging}

Few decade later, some researchers i.e., Kirk wood, (1977), Kirk wood and Rose, (1991) have postulated in their finding that, early reproduction trade off against late survival, but through which optimal resource allocation strategic rather than pleiotropic genes plays an important role in aging.

Apart from above theories, some important contribution have also made by several research investigators during early $50^{\text {th }}$ and $60^{\text {th }}$ decades onwards on the evolution of aging in insects are Medawar, (1952), Williams, (1957), Strehler, (1960 \& 1962) and Charles worth and Stephen, (2001). The evolutionary phenomenon of aging gives varies twisted prediction of which highlights the extrinsic mortality should be negatively related with the intrinsic life span (i.e., life unaffected by environmental factors). Moreover, most later on $60^{\text {th }}$ and $70^{\text {th }}$ century onwards several well-known researchers have worked on aging related aspects by utilizing different insects including mulberry silkworm Bombyx mori are Gerald et al., (2002) in Bat, Carey and Judge, (2001) in mammals, birds, reptiles, fish, Gavrilob and Gavrilova, (1991) in drosophila melanogaster, mice and dogs, Brooks et al., (1994) in nematodes, Johnson, (1987 \&1990) in mosquitoes, Gavrilov, (1980) in human lice (Pediculum humanus) and utilizing mulberry silkworm Bombyx mori, Murakami, (1989a and 1989b), Osanai, (2003), Murthy, (2008), Doddaswamy and Subramanya, (2007), Anantha and Subramanya, (2012) and Ramya and Jagadeesh kumar, (2017).

\section{Phenomena of longevity in Silkworm, Bombyx mori}

The silkworm Bombyx mori being monophagous insects has been utilizing one of the popular genetical model organisms to investigate various aspects of biological, genetical, molecular, physiological, biochemical, nutritional and climatic aspects, gerontology etc. Further, several group of insects have different lifespan including lepidopteron silkworm Bombyx mori (Table 1) and having egg, larva, pupa and adult stages in its whole developmental stages of its life cycle (Fig. 4). There are numerous important steps for selecting silkworm insect has a model organism to study the aging phenomenon are 1) To observe the relatively shorter lifespan phenomenon (lesser than 25 days in case of larvae) depending upon races/strains (Nirmal 
kumar and Sreerama Reddy, 1994), 2) To observe the availability of stocks containing altered genes, 3) For maintenance of the silkworms in germplasm rearing stations with easy handling for the rearers (Krishnaswami, 1978), 4) The phenomenon of climatic and genetic manipulations that varies lifespan of silkworms, 5) Influence of molecular genetical mechanism, 6) To observe the phenomenon of sequencing of the silkworm genome, 7) To observe the phenomenon of dissecting complex biological parts such as head, thorax, abdomen, nerve and circulatory systems, silk gland and sex identification etc, 8) To observe the silkworm behaviour (moulting, under moulting feeding and diseases affected worms phenomenon, etc), 9) To observe in detailed information in regards to pupal and adult longevity (Ramya and Jagadeesh kumar, 2017), 10) In addition, the other aspects of biology of physiological and biochemical of silkworm insect are of particular advantage for aging work including its life history, which has divided into morphological features, duration of growth/development (egg, larvae, pupa and adult, etc) can be readily distinguished. In several organisms visually distinguishing of mature aging adults from immature or juvenile phases is not simple. In drosophila for example development is restricted only to the embryo, larva, pupa and adult life. However, in silkworm Bombyx mori the adult fly is sexually mature and hence, considered as a mature aging adults. Post mitotic fully differentiated cells except for cell gonads and few cells in gut (Bozuck, 1972 and Ito and Hotta, 1997). Other organism such as human being carried many organ system i,e gastrointestinal, dermatological and hematopoietic systems are constituted by continuous cell replacement. Further, several other organs, brain and heart have rarely excess of new neurons or cardiac cells (Stephen et al., 2003). Longevity may be said different meaning, in different situation, few reports suggesting that by focusing primarily on above said phenomenon, then involved in trying to understand the physiological, biochemical, biological, genetical and molecular level and changes that take place in cells and different organs over the time and situation. The insects such as silkworm Bombyx mori, which is almost similar to the drosophila melanogaster for some aspects as said above being utilised as an excellent model system of aging studies in the different well equipped laboratories and few reports were made by Murakami, (1989a and 1989b), Osanai, (2003), Murthy, (2008), Doddaswamy and Subramanya, (2007), Anantha and Subramanya, (2012) and Ramya and Jagadeesh kumar, (2017) utilizing silkworm as a model organism for the study of ageing related aspects.

\section{Intrinsic factors effects on aging}

Intrinsic aging is a term used to describe cutaneous aging of the skin and other parts of integumentary system. In other words intrinsic aging is a phenomenon where influencing of internal physiological factors and this intrinsic aging is popularly known as chronologic aging. Because where occurrence of inherent degenerative process from the process internal physiological factors decreases, such factors are both qualitative and quantitative in nature.

\section{Physiological and biological factors influence on aging}

Aging is a process, which involving under influences both intrinsic and extrinsic factors. The intrinsic factors are influences some extends greater than extrinsic factors but both plays coordinated with in an organism. Recently, gerontologist and physiologist are researching on aging of silkworm and other model organism and realizing how the decline physiological and biological activities of silkworm insects continuously to be one of the remarkable question with relevant to aging research. But it has been difficult to address yet in detailed by gerontologists.. 
Table.1 Longevity of different group of insects including lepidopteran silkworm Bombyx mori

\begin{tabular}{|c|c|c|c|c|}
\hline Insects group & Male (days) & \multicolumn{2}{|c|}{ Female (days) } & Reference \\
\hline \multicolumn{5}{|c|}{ Longevity of insects belonging to Dipteran group } \\
\hline \multicolumn{5}{|c|}{ Drosophila melanogaster } \\
\hline Wild (line 107) & 38.1 & 40.1 & \multicolumn{2}{|r|}{ Gonzalez (1923) } \\
\hline Vestigial mutant & 15.0 & 21.0 & & \\
\hline \multicolumn{5}{|l|}{ Drosophila subobscura } \\
\hline $\begin{array}{l}9 \text { inbred lines (average) } \\
\text { (1959) }\end{array}$ & 40.0 & 36.4 & \multicolumn{2}{|r|}{ Maynard-Smith } \\
\hline 4 outbred population (average) & 56.8 & 60.0 & \multirow{2}{*}{\multicolumn{2}{|c|}{ Rockstein and Lieberman }} \\
\hline $\begin{array}{l}\text { Musca domestica } \\
\text { (1959) }\end{array}$ & 17.5 & 29.0 & & \\
\hline Musca vicina & 20.8 & 23.3 & \multirow{3}{*}{\multicolumn{2}{|c|}{$\begin{array}{l}\text { Feldman-Muhsam and } \\
\text { Muhsam (1945) } \\
\text { Kershaw et al. (1953) }\end{array}$}} \\
\hline Calliphora erythrocephala & 35.2 & 24.2 & & \\
\hline Aedes aegypti & - & 15 & & \\
\hline \multicolumn{5}{|c|}{ Longevity of insects belonging to Lepidopteran group } \\
\hline $\begin{array}{l}\text { Silkworm Bombyx more (unmat } \\
\text { (1932) }\end{array}$ & d) 11.9 & 11.9 & \multicolumn{2}{|c|}{ Alpatov and Gordeenko } \\
\hline Silkworm Bombyx more (mate) & 15.2 & 14.2 & \multirow{2}{*}{\multicolumn{2}{|c|}{ Pearl and Miner (1936) }} \\
\hline Acrobasis caryae & 6.5 & 7.3 & & \\
\hline Fumea Crassiorella (unmated) & - & 5.5 & \multicolumn{2}{|r|}{ Matthes (1951) } \\
\hline Fumea Crassiorella (mated) & - & 2.3 & \multirow{2}{*}{\multicolumn{2}{|c|}{ MacArthur and Baillie }} \\
\hline $\begin{array}{l}\text { Samia cecropia } \\
\text { (1932) }\end{array}$ & 10.4 & 10.1 & & \\
\hline Samia californica & 8.7 & 8.8 & & \\
\hline Tropea luna & 5.9 & 6.0 & & \\
\hline Philosamia cynthia & 5.9 & 7.1 & & \\
\hline \multicolumn{5}{|c|}{ Longevity of insects belonging to Hymenopteran group } \\
\hline \multicolumn{5}{|l|}{ Apis mellifera } \\
\hline Summer bees & - & & 35 & Ribbands, (1952) \\
\hline Winter bees & - & & 350 & Maurizio, (1959) \\
\hline \multicolumn{5}{|l|}{ Habrobracon juglandis } \\
\hline Wild type & 24 & & 29 & Georgiana, (1949) \\
\hline Small wings, white eyes mutant & 20 & & 24 & \\
\hline \multicolumn{5}{|c|}{ Longevity of insects belonging to Orthopteran group } \\
\hline Blatta orientalis & 40.2 & & 43.5 & Rau, (1924) \\
\hline $\begin{array}{l}\text { Periplaneta americana } \\
(1942)\end{array}$ & 200 & & 225 & Griffiths and Tauber, \\
\hline Schistocerca gregaria & 75 & & 75 & Bodenheimer, (1938) \\
\hline \multicolumn{5}{|c|}{ Longevity of insects belonging to Coleopteran group } \\
\hline Tribolium confusum & 178 & & 195 & Park, (1945) \\
\hline Tribolium madens & 199 & & 242 & \\
\hline Procrutes & 374 & & 338 & Labitte, (1916) \\
\hline Carabus & 323 & & 386 & \\
\hline Melolontha vulgaris & 19 & & 27 & \\
\hline
\end{tabular}


Fig.1 Evolution of different insects in percentage (Source from Grimaldi and Engel, 2005)

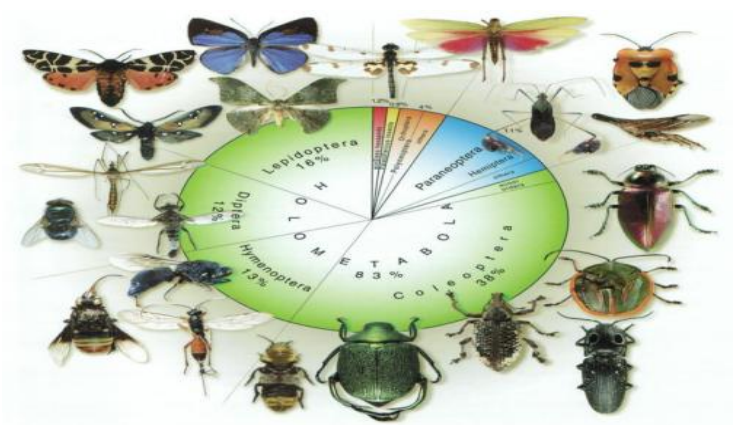

Fig.2 Characteristics of aging process. Fig.3 Theories of aging (Classification) (Source: IUMB Life, 2007)
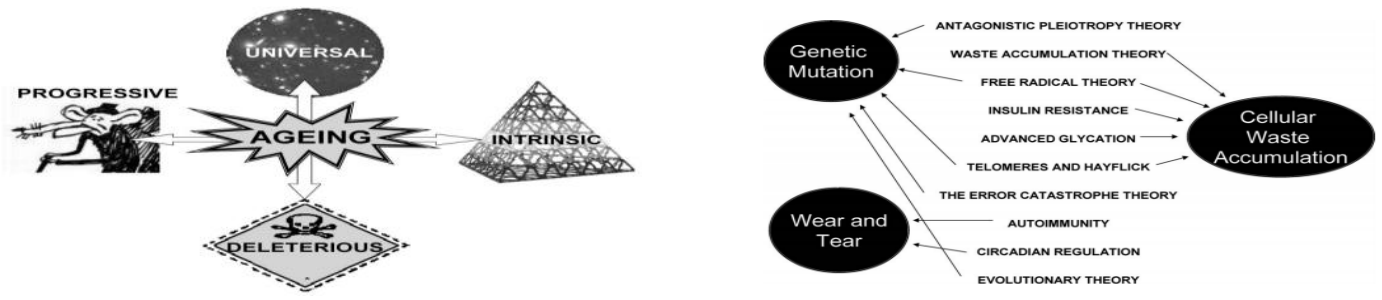

Figure.4 Life cycle of the silkworm Bombyx mori (Source: Image belongs to Joanna Rose Tidey)

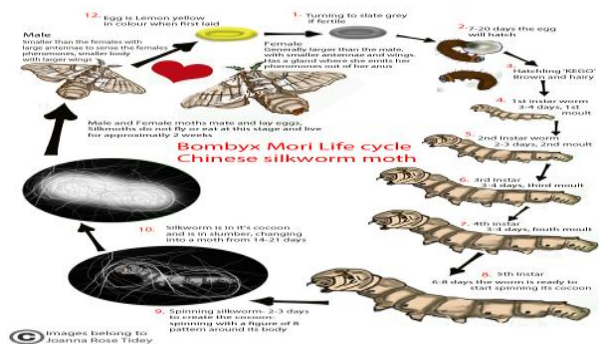

Fig.5 Phylogenetic cluster showing relative reproductive lifespan of various insect groups (taxa), Lepidopteran (Silkworm, Bombyx mori) and Dipteran (Drosophila melanogaster) groups are showing closely relative reproductive lifespan. (Source: Nature, Keller \& Genoud, 1997)

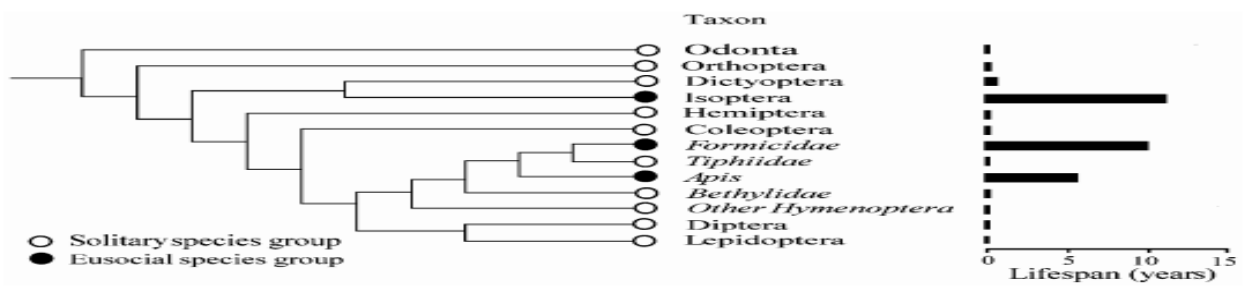

Recently, several gerontologists are with relevant to physiological and concentrating on importance of aging process biochemical factors in different insects and 
also in silkworm Bombyx mori. Further, Keller \& Genoud, (1997) showed the relationship between lepidopteron (Silkworm, Bombyx mori) and Dipteran (Drosophila melanogaster) groups were closely related with reproductive lifespan (Fig. 5). In drosophila research was done on complex organ and endocrine system that were allow to study the role of conserved signalling transduction path ways with help of genetic and oxidative stress and metabolic changes along with between signalling systems insulin respecter (Tatar et al., 2003), target of rapamycin (TOR) and Jun N-terminal kinase (JNK) have been reward some of the important documentary evidences on aging by well known researchers.

However, Lim et al. (2005) was reviewed on physiological activities of aging in drosophila and suggested that insect sleep and organ specific aging as also been remained vital to understand the aging phenomena in drosophila. Further, Tettweiler et al. (2005) were unravel in their research, the changes of several energy compounds with response signalling pathway and amino acids and it is to noted that the size, growth and longevity of insects regulate in drosophila. However, regulation of metabolism as well as lifespan is depends on dTORacts downstream of dFOXOwhich are inter connected with INR pathway(Luong et al. 2006).Earlier study of Wang et al. (2005) have focused the cross talk between INR, TOR and JNK signalling in aging. Moreover, another report revealed that decline of lifespan observed due to upregulating the levels of antioxidants (Bayne $e t$ al., 2005). On other hand some evidence by Fridell et al. (2005) whose research says the increase of longevity by decreasing in ROS generation because human uncoupling protein 2 (Lucpz) in the mitochondria of adult fly, neurons and human SOD in adult fly motor neurons. Above statement directly supports to the advantage of utilizing drosophila as a model organism for testing the various physiological functions of human proteins with relevant to aging.

Nevertheless, the study by Partridge et al. (2005) revealed not much significant differs of ROS production and metabolic rate compare to controls. In some extent, several researches proved that, Shaw et al. (2000) noted insects flies use to showed remarkable sleeping characteristic features, this study revealed the rate of sleep correlated with the fragmentation of longevity and that leads to shortening of lifespan. Further, irregular sleeping causes physiological aging disorders (Koh et al. 2006). In some cases, the physical activity changes said to be effects on longevity and that may do so through affecting on metabolic rates, the forced decrease of physical activities in house flies through housing single fly in normal containers that will not allow them to fly hence enhances the longevity (Buchan and Sohal, 1981). Few reports suggested like, in mutants $\mathrm{K}^{+}$channels (hyperkinetic, shaker) increases physical activity and shorten life span (Trout and Kaplan, 1970).

\section{Extrinsic factors effects aging}

Extrinsic aging is a word which also involves cutaneous aging, which is also part of the integumentary system. The extrinsic aging is also known as photoaging. Because of the radiation which effects more among the all factors which influence on aging. Hence, the term extrinsic aging is often referred as photoaging (Gilchrest, 1998 and Uitto et al., 1998).

In conclusion, different group of insects in general and lepidopteron silkworm Bombyx mori in particular are immensely provide a unique system for aging investigations under advanced scientific world. Based on inferences from different phenomenon that is 
physiological, biochemical, ecological, cytological, genetical and molecular studies, it seems like that, the striking longevity play an important role on over all the benefits/income from highly economical important insects like, Bombyx mori in silk industry. A dramatic progress have been achieved right from the early years to modern year through identifying specific physiological, biochemical, genetical, molecular knowledge, etc., which extends/decrease the aging pattern of different group of insects including silkworm Bombyx mori by utilizing different research procedures and techniques in the life science. Hence, it is noteworthy that, the said phenomenon of aging viz., intrinsic and extrinsic factors are basically helps to understand the longevity and dramatic life span differences existed between each and every races/breeds/hybrids of the silkworm Bombyx mori, which are fundamental base to further research investigations to be explored several evolutionary information relevant to shortened the lifespan. The gathered information herein this review paper will glance a great promise and encourage to shape fundamental answer for micro or macro level researchers to both gerontologists and evolutionary biologist from a view point of economical and scientific growth \& development of the silk industry in India and other part of the world.

\section{Acknowledgement}

The authors wish to express sincere thanks to University Grants Commission for providing the funds. I express my thanks to the Chairman, Department of Studies in Sericulture Science, University of Mysore, Mysuru for extending facilities to conduct this review work.

\section{References}

Anantha R and Subramanya G. 2009. Correlation studies between adult life span and commercial characters of the silkworm, Bombyx mori. MyScience, 56-63.

Bayne AC, Mockett RJ, Orr WC and Sohal RS. 2005. Enhanced catabolism of mitochondrial superoxide/hydrogen peroxide and aging in transgenic Drosophila. Biochem J. 391:277-84.

Bozuck, AN. 1972. DNA synthesis in the absence of somatic cell division associated with ageing in Drosophila subobscura. Exp. Gerontol. 7, 147156.

Brooks, H.E., Doswell III, C.A and Cooper, J. 1994. On the environments of tornadic and nontornadic mesocyclones. Am. Meteorol. Soc. 9, 606-618.

Buchan PB and Sohal RS. 1981. Effect of temperature and different sex ratios on physical activity and life span in the adult housefly, Musca domestica. Exp Gerontol. 16(3): 223-8.

Chapman, A.D. 2006. Number of living species in Australia and the World, Canberra: Australia biological resource study. pp.60.

Charlesworth 1980. Evolutionary biology of aging. Book, published by Oxford Univ.

Charlesworth D and Stephen Wright. 2001. Breeding systems and genome evolution-Review. Current opinion in genetics and genome evolution. 11(6): 685-690.

Cohn A.A., de Magalhaes J.P and Gohil K. 2010. Ecological, biomedical and epidemiological approaches to understand oxidative balance and ageing: what they can teach each other. Functional Ecology 24, 9971006

Doddaswamy MS and Subramanya G. 2007. Studies on the adult lifespan of multivoltine and bivoltine races of the silkworm, Bombyx mori L. Indian J.Seric. 46(2):106-108. 
Erwin and Terry L. 1982. Tropical forests: their richness in coleoptera and other arthropod species, Coleopt. Bull. 37, 74-75.

Fridell YW, Sanchez-Blanco A, Silvia BA and Helfand SL. 2005. Targeted expression of the human uncoupling protein 2 (hUCP2) to adult neurons extends life span in the fly. Cell Metab. 1:145-52.

Gavrilov L. A and Gavrilova N. S. 1991. The Biology of Life-Span: A Quantitative Approach. Harwood academic publisher, Chur, Switzerland. pp. 326385

Gavrilov LA. 1980. Study of life span genetics using the kinetic analysis. Thesis, Moscow, Russia: Moscow State University.

Gerald S. Wilkinson and Jason M. South. 2002. Life history, ecology and longevity in bats. Aging Cell. 1, 124 131.

Gilchrest, B. 1998. The UV-Induced SOS Response: Importance to Aging Skin. The Journal of Dermatology. 25(12): 775-777.

Hamilton, W.D. 1966. The moulding of senescence by natural selection. J. Theo. Biol. 12, 12-45.

Ito K and Hotta, Y. 1997. Proliferation pattern of postembryonic neuroblasts in the brain of Drosophila melanogaster. Developmental biology. 149(1): 134148.

James R Carey and Debra S Judge 2001. Life span extension in humans is selfreinforcing: a general theory of longevity. Population and development review. 27(3): 411-436.

Johnson, TE. 1990. Increased life span of age1 mutants in Caenorhabditis elegans and lower Gompertz rate of aging. Science, 249, 908-912.

Keller, L and Genoud, M. 1997. Extraordinary lifespans in ants: a test of evolutionary theories of ageing. Nature. 389, 958-960

Kirkwood TBL and Rose M.R. 1991. Evolution of senescence: late survival sacrificed for reproduction. Philos. Trans. Soc. Lond. Biol. Sci. 29; 332(1262):15-24.

Kirkwood TBL. 1977. Evolution of ageing. Nature. 270, 301-304.

Koh K, Evans JM, Hendricks JC and Sehgal A. 2006. A Drosophila model for ageassociated changes in sleep: wake cycles. Proc Natl Acad Sci U S A. 103:13843-7.

Krishnaswami S. 1978. New techniques of silkworm rearing. CSRTI Bulletin, CSRTI, Mysore, India, 2:1-23.

Lim,H.Y., Bodmer, R and Perrin, L. 2005. Drosophila Aging 2005/06. Exp Gerontol. 41(12): 1213-1216.

Luong N, Davies CR, Wessells RJ, Graham SM, King MT, Veech R, Bodmer R and Oldham SM. 2006. Activated FOXO-mediated insulin resistance is blocked by reduction of TOR activity. Cell Metab. 4:133-42.

McGraw K., Cohen A.A., Costanini D and Horak P. 2010. The ecological significance of antioxidants and oxidative stress: a marriage between mechanistic and functional perspectives. Functional Ecology 24, 947-949

Medawar PB. 1952. An Unsolved Problem of Biology. H. K. Lewis, London.

Medvedev, ZA.1990. An attempt at a rational classification of theories of aging. Biol.Rev.65,375 398.

Murakami A. 1989. Genetic studies on the silkworm adult life span Heredity of the short adult life span (sdi). Annual Report, National Institute of Genetics (Japan). 39: 67-68.

Murakami A. 1989. Genetic studies on the silkworm adult life span: Heredity of the short adult life span (sdi). Ann. 
Rep., National Institute of Genetics (Japan). 39:69-70.

Niramal Kumar, S and Sreerama Reddy, G. 1994. In: Silkworm Breeding. (Ramireddy, G.S. ed.) Oxford and IBH Publishing Co. Pvt. Ltd., 1998, pp. 63-68.

Osanai M. 1978. Longevity and body weight loss of the silkworm moth, Bombyx mori, varied by different temperature treatments. Experimental gerontology. 13(6): 375-388.

Partridge, L., Gems, D and Withers, D. J. 2005. Sex and death: what is the connection? Cell, 120, 461-72.

Ramya, MN and Jagadeesh kumar, TS. 2017. Biochemical changes in relation to growth and longevity of pupal and adult stages of selected voltine groups of the silkworm, Bombyx mori L. Thesis, University of Mysore.

Shaw PJ, Cirelli C, Greenspan RJ and Tononi G. 2000. Correlates of sleep and waking in Drosophila melanogaster. Science. 287:1834-7.

Stephan L, Helfand and Blanka Rogina. 2003. Genetics of aging in the fruit fly, Drosophila Melanogaster. Annu. Rev. Genet, 37: 329-348.

Strehler, 1960. General theory of mortality and aging. Science. 132(3418): 14-21.

Strehler, B. 1962. Time, cells and aging. Academic Press, New York.

Tatar, M., Bartke, A and Antebi, A. 2003. The endocrine regulation of ageing by insulin-like signals. Science, 299,

\section{6-51}

Tettweiler G, Miron M, Jenkins M, Sonenberg N and Lasko PF. 2005. Starvation and oxidative stress resistance in Drosophila are mediated through the eIF4E-binding protein, d4E-BP. Genes Dev. 19:1840-3.

Trout, W.E and Kaplan, W.D. 1970. A relation between longevity, metabolic rate, and activity in shaker mutants of Drosophila melanogaster. Exp. Gerontol. 5: 83--92. (Export to RIS)

Uitto, L., Pulkkinen, AM and Christiano. 1998. The molecular basis of the dystrophic forms of epidermolysis bullosa J-D Fine, EA Bauer, J McGuire, A Moshell (Eds.), Epidermolysis bullosa: Clinical, Epidemiologic and Laboratory Advances, and the Findings of the National Epidermolysis bullosa Registry, Johns Hopkins University Press, Baltimore, MD (1998) in press. Wang MC, Bohmann D and Jasper H. 2005. JNK Extends Life Span and Limits Growth by antagonizing cellular and organism-wide responses to insulin signaling. Cell. 121: 115-25.

Williams GC. 1957. Pleiotropy, natural selection and the evolution of senescence. Evolution. 11: 398-411.

Wilson, E.O. 2009. Threats to global diversity. Retrieved May -7- 2009.

Meng Xu, Feifei Zhu and Khening C. 2017. Silkworm: A promising model organism in life science. Journal of insect science. 17(5): 97; 1-6.

\section{How to cite this article:}

Ramya, M.N., Shivkumar and Jagadeesh Kumar, T.S. 2018. The Silkworm, Bombyx mori: A Promising Model Organism to Study the Longevity - A Review. Int.J.Curr.Microbiol.App.Sci. 7(11): 3433-3442. doi: https://doi.org/10.20546/ijcmas.2018.711.394 